\title{
Título: O Deslocamento Feminino no Romance Contemporâneo
}

\author{
A U T O R : Carlos Magno Gomes*
}

RESUMO: Este artigo retoma a reflexão acerca da identidade de gênero nos romances de Lya Luft e Helena Parente Cunha por meio dos estudos de gênero. Parte-se de uma concepção feminista para a análise da paródia do deslocamento da mulher como uma forma de resistência ao patriarcado. Tal contestação é sugerida pela metáfora da morte da mãe tradicional na ficção dessas autoras. Metodologicamente, exploram-se conceitos de paródia, de Hutcheon, e de deslocamento de gênero, de Butler.

PALAVRAS - CHAVE: identidade de gênero; espaço social; narrativa contemporânea.

A B S T RACT: This paper takes up the reflection of gender identity in novels by Lya Luft and Helena Parente Cunha, by means of gender studies. It starts with a feminist conception for the analysis of parody of women's movement as a form of resistance to the patriarchy. This challenge is suggested by the metaphor of the traditional mother's death in these authors' fiction. Methodologically, the concepts of parody, by Hutcheon, and displacement of gender, by Butler, will be explored.

KEYWORDS : gender identity, social space, contemporary narrative.

\section{Preliminares feministas}

Na literatura contemporânea, há diferentes formas de crítica ao patriarcado, como a representação da mulher transgressora no espaço da família. Essa forma de contestação está presente nos textos de Lygia Fagundes Telles, Nélida Piñon, Lya Luft, Marina Colasanti, Helena Parente Cunha, entre outras. Tais autoras privilegiam mulheres transgresras que deixam de lado a identidade tradicional por não se identificarem com a imposição patriarcal. Essas personagens podem ser vistas como parte de uma estratégia feminista por não aceitarem a submissão aos papeis femininos. Nesse sentido, o significado da imagem da transgressora reforça a ideia do deslocamento da identidade de gênero como um movimento de resistência na tradição da autoria feminina brasileira.

Neste ensaio, retomamos alguns pontos-chave acerca da identidade de gênero na ficção feminina, como o deslocamento espacial da mulher e a paródia da família patriarcal. Para isso, partimos de uma análise literária que não deixa de lado as opções estéticas como um lugar de resistência ideológica da escritora brasileira no século XX. No primeiro moment' d"o, “"'ressaltamos as contribuições dos estudos de gênero para a análise do texto literário a partir do questionamento dos papeis masculinos e femininos. Em seguida, analisamos como o deslocamento de gênero pode ser visto como um lugar de produção de novos pertencimentos identitários para a mulher na ficção de Lya Luft e Helena Parente Cunha.

Culturalmente, essas escritoras projetam um espaço de resistência feminista ao construírem identidades de gênero em deslocamento. Por esse princípio, as opções de gênero podem ser identificadas nas diferentes opções identitárias, fora do binarismo entre o "masculino" e o "feminino". Essa peculiaridade de gênero faz parte da crise das identidades pós-modernas que não apresentam um pertencimento fixo ao se deslocarem entre o "deve ser" e o "é" de uma identidade (BAUMAN, 2005, p. 26). Nessa perspectiva, a representação da mulher em trânsito

\footnotetext{
* Prof. Adjunto de Literatura do Campus Prof. Alberto Carvalho e do Mestrado em Letras da UFS. Doutor em Literatura pela UnB, com pósdoutorado em Letras Vernáculas pela UFR. Contato: calmag@bol.com.br
} 
faz parte do imaginário crítico de escritoras que rompem a fronteira do espaço patriarcal. Tal relação entre lugar e identidade pode ser identificada no roteiro da narrativa, isto é, na forma como o texto se desdobra ideologicamente, já que o pensamento feminista pode ser visto tanto na forma narrativa como nas opções identitárias das personagens.

A partir dos estudos de gênero, reconhecemos que a identidade da mulher moderna é fruto da repetição de performances contestadoras, e que este longo processo de identificação e de escolha envolve rejeição e aceitação. Nesse percurso, a identidade da mulher não é apenas determinada por normas, uma vez que a construção de tal identidade passa por um "processo regulado de repetição que tanto se oculta quanto impõe suas regras, precisamente por meio da produção de efeitos substancializantes” (BUTLER, 2003, p. 209). Essa perspectiva fica mais ambígua no texto literário, já que a identidade de gênero está atravessada pelo dialogismo textual.

Na narrativa contemporânea, o pertencimento da identidade feminina passa a ter um viés político, visto que essa literatura passa a valorizar a alteridade e a diferença como parte da identidade tradicional. Nesse processo, torna-se relevante reconhecer que a identidade de gênero é uma construção e um resultado de um ato de naturalização, pois "é um "ato", por assim dizer, que está aberto a cisões, sujeito a paródias de si mesmo, a autocríticas àquelas exibições hiperbólicas do "natural" que, em seu exagero, revelam seu status fundamentalmente fantasístico" (BUTLER, 2003, p. 211). Dessa forma, qualquer identidade faz parte de um ciclo de identificação em que o novo e o velho se encontram em um espaço rasurado, pois já não cabe a forma antiga; todavia não podemos deixar de lado as "questões-chave" dos novos questionamentos identitários (HALL, 2000, p. 104).

A partir desse enfoque de gênero, ressaltamos que, na literatura, a interpretação deve evitar o ângulo unidirecional, pois o espaço estético antes de tudo "recria e transforma, produzindo cortes e intervalos entre corpo, trajeto biográfico-social, posições de gênero, traços subjetivos e figurações textuais” (RICHARD, 2002, p. 161). Tal premissa é fundamental para entendermos as tensões de gênero em jogo na literatura, já que nas representações identitárias há "significados suplementares sobre os quais não temos qualquer controle, que surgirão e subverterão nossas tentativas para criar mundos fixos e estáveis" (HALL, 2006, p. 41). Nessa direção, os estudos de gênero reconhecem o quanto a identidade é ambivalente e paradoxal, pois "mesmo que uma identidade sexual - como ser mulher, ser homem, ser lésbica, ser gay - tenha servido de base para importantes comprometimentos políticos, tais identificações são precárias e contingentes em termos culturais e históricos”. (FUNK, 2011, p. 67).

A revisão das identidades patriarcais foi fortalecida pela crítica feminista, que não se projeta nem de forma homogênea, nem monolítica, pois se constitui numa complexa rede de práticas ideológicas que contestam a violência e a opressão feminina. Tanto quanto a teoria, o texto literário não apresenta estratégias homogêneas para o descentramento do discurso patriarcal. Assim, a identidade de gênero pode ser vista como um processo sempre em movimento, que não apresenta fixidez, pois se trata de uma prática social plural. Daí a importância do reconhecimento das tensões em torno das identidades e dos encontros e desencontros de gênero, valorizando o lugar de suturas e rasuras de um sujeito de fronteiras (HALL, 2000, p. 104).

Em relação à influência do pensamento feminista nos estudos literários, destacamos a pesquisa de Elódia Xavier sobre a representação da mulher na ficção. Ela identifica a presença da violência simbólica e a falência da família patriarcal como particularidades da autoria feminina. Essa pesquisadora identifica diversas personagens femininas que apontam esse questionamento, 
desde o "corpo disciplinado", que ressalta a norma, passando pelo "corpo degenerado" que avulta as regras sociais como uma forma de resistência até o "corpo liberado", expressando a liberdade da mulher como mentora de sua vida social e psíquica (XAVIER, 2007, p. 22).

Por um olhar mais historicista, Constância Lima Duarte destaca que a luta da mulher contra a violência e opressão sempre esteve na pauta da feminista brasileira. Tal envolvimento político da intelectual feminista já está presente na produção pioneira de Nísia Floresta sobre os direitos das mulheres no século XIX e passa pela divulgação de jornais e revistas voltados para o público feminino na primeira metade do século XX. Com a luta pelo direito ao voto e pelo controle da maternidade, o feminismo ganhou uma face mais politizada ao se posicionar contra todos os tipos de censura durante o período da ditadura militar (DUARTE, 2007, p. 132). Essa luta social foi incorporada pela escritora brasileira ao descrever a trajetória de mulheres transgressoras e independentes.

Para completar essas preliminares, destaca-se a importância do uso da paródia como uma estética de resistência no caso do texto literário contemporâneo, pois ela atua como parte de um projeto feminista de questionamento das normas sociais. Nesse sentido, vale destacar que, ao mesmo tempo em que amplia os temas romanescos, a escritora brasileira explora a paródia como uma forma de descentramento da família patriarcal, pois "a paródia atua como um expediente de elevação da consciência, impedindo a aceitação dos pontos de vista estreitos, doutrinários, dogmáticos de qualquer grupo ideológico” (HUTCHEON, 1989, p. 131).

Assim, valorizamos o plano cultural como princípio norteador do estudo da identidade de gênero, para repensarmos o texto de autoria feminina como um espaço de libertação do discurso de gênero das amarras disciplinadoras da sociedade. Nesta proposta, destacamos que a crítica ao patriarcado é construída esteticamente por meio do olhar paródico e metanarrativo. Tais características são próprias do texto pós-moderno, que apresenta diálogos com outros textos e contextos por sua especificidade metanarrativa e por reconhecer "conscientemente e autocriticamente a sua própria natureza" (HUTCHEON, 1989, p. 40).

Tal particularidade do texto paródico merece destaque por explorar a ironia, a sátira e, por vezes, a caricatura da família como maneiras de contestar o espaço da casa. Seguindo essa perspectiva, a escritora contemporânea incorporou a luta da mulher contra a opressão como parte da literatura. Na tentativa de explorar tais questões culturais, a seguir, analisaremos as marcas do modelo paródico de crítica ao patriarcado na ficção de Lya Luft e de Helena Parente Cunha.

\section{A maternidade em guestão em Lya Luft}

Ao incorporar estratégias de questionamento social oriundas do pensamento feminista, a escritora brasileira contemporânea intensificou o deslocamento da mulher para fora da família patriarcal. Lya Luft é um exemplo desse engajamento feminista, pois suas obras apresentam uma galeria de personagens rejeitadas pelas normas patriarcais. Seu primeiro romance, As parceiras (1980), traz essa preocupação ao deslocar a protagonista de um casamento fracassado para um mergulho pessoal em suas escolhas individuais. Esse questionamento dos papeis femininos é uma constante em sua obra. Muitas de suas protagonistas não conseguem se realizar no espaço da família patriarcal e, por isso, optam por deslocamentos para fora da casa.

Em O quarto fechado (1984), Lya Luft apresenta a particularidade do deslocamento feminino por meio da protagonista, Renata, que atravessa uma noite ao lado do caixão do filho suicida. Ela busca explicações para seu fracasso como mãe. Nessa narrativa, o espaço da família é claustrofóbico para todos os estranhos, que juntam os cacos que sobraram dessa opressão. 
Renata avalia os conflitos familiares que anteciparam aquela cena final. No meio de uma crise pessoal, ela rejeita a identidade de mãe e de esposa e se ressente de ter abandonado uma carreira de pianista de sucesso para se dedicar ao casamento.

Nesse processo de deslocamento pelo passado, Renata busca um espaço subjetivo que corresponda ao do filho morto. Assim, ela opta por reminiscências interiores na tentativa de se salvar. Ela se desloca pelas entranhas da morte para construir novas imagens de si, a partir da fusão do quadro "llha dos mortos" e do velório de Camilo, um "espetáculo inaugural” (LUFT, 1991, p. 83) de uma travessia simbólica da mulher silenciada. Seu desespero vai sendo tecido mentalmente no avançar das horas. Enquanto o filho "ostentava aquela máscara solene: cera, gelo, uma nova sabedoria” (LUFT, 1991, p. 13), ela se perdia em suas memórias trágicas de um casamento que não deu certo.

Tal especificidade da representação de uma mulher avessa à maternidade reforça o olhar paródico dessa situação, pois o próprio texto é visto como parte de um jogo social de questionamento dos papeis femininos. Além dessa subjetividade espacial, o ponto de vista paródico está presente nas diversas metáforas da morte: o enterro do filho, o fim do casamento, a constatação do fracasso da maternidade. Tais aspectos polifônicos na estrutura e no estilo de O quarto fechado ressaltam seu tom paródico (HUTCHEON, 1989, p. 93). Tal versão da família também possibilita um questionamento dos limites entre os papeis femininos e masculinos.

Na família, o comportamento de Renata sempre foi visto como uma ameaça para o marido, pois ela está constantemente em crise com o casamento. Nesse caso, sua liberdade é muitas vezes descrita como uma ameaça à família, e sua posição de artista como uma ameaça à ordem do marido, pois “a 'individualização' em excesso é ambígua. Tal processo oscila entre o sonho e o pesadelo, e não há como dizer quando um se transforma no outro" (BAUMAN, 2005, p. 38). Dessa forma, a ambiguidade do pertencimento identitário de Renata é experimentada pelo patriarca, Martim. Para ele, Renata é um pesadelo, já que não se enquadra no papel social de esposa dedicada.

Assim, essa narrativa possibilita uma leitura mais sofisticada da identidade de gênero ao sobrepor uma mãe fora do lugar diante dos desajustes familiares. No processo metafórico, ao vivenciar a morte do filho, Renata também se enterra, pois se identifica com ele na travessia da vida para a morte: "Renata mirava Camilo: por onde andaria agora? Morto, parecia-lhe um pouco menos misterioso” (LUFT, 1991, p. 62).

De certo modo, essa constatação indica ser a vida, para a personagem, fonte de mistério, o que igualmente aponta para a desconexão entre o "dever ser" e o "ser de fato". Por meio desse processo metafórico de identificação mãe/filho já sem as misteriosas "amarras" da vida, O quarto fechado possibilita a interpretação da morte da identidade materna tradicional como um rito de iniciação necessário para que a representação patriarcal da mãe/esposa/mulher seja transgredida. O fracasso dessa representação é muito bem articulado entre a subjetividade da artista, a opressão do marido e a carência do filho morto.

Além desses conflitos identitários, no plano estético da narrativa há um jogo de interação entre o quadro e o velório. Assim como nos presentes ao velório, na pintura llha dos mortos, "tudo vibrava, palpitava, por trás da cena imóvel” (LUFT, 1991, p. 19). Tal relação nos sugere a ruptura das fronteiras físicas dos dois espaços, pois quadro e realidade interagem pelo olhar de Renata, que identifica um barco em processo de travessia: "Um barco dirigia-se para lá; na proa, em pé, um vulto embuçado" (LUFT, 1991, p. 19). 
Ao sobrepor as fronteiras do quadro às de seu contexto, Renata consegue se ver melhor. Essa travessia se completa quando percebe que ela própria guiava o filho para a llha: "chegando ao fim das suas forças, Renata compreendeu: Não era um barqueiro: era uma mulher. O vulto da proa era ela, a Amada de Camilo: Thanatos" (LUFT, 1991, p. 130). Dessa forma, Renata completa seu trajeto revelador de si mesma: uma mãe que guia o filho pelos espaços da morte. Portanto, a narrativa de Lya Luft ressalta uma premissa feminista na qual o conceito de mulher é "algo sempre incompleto e em transformação" (FUNK, 2011, p. 71).

Assim, sem a consolidação de uma maternidade tradicional, ela deixa aberta uma perspectiva feminista, pois com o filho, Renata enterra também um casamento patriarcal do qual não queria mais participar. A partir dessa perspectiva, O quarto fechado não registra uma identidade fixa nem concluída para o sujeito feminino, optando por representar o deslocamento da identidade da mãe. A sofisticação dessa construção narrativa foi retomada por Lya Luft com A sentinela (1994), obra em que a mulher ganha um espaço para pensar seu processo de pertencimento identitário como algo sempre em movimento. Com tais opções culturais, Lya Luft atualiza sua ficção por meio de uma perspectiva ideológica feminista cuja preocupação é o desvelamento das normas patriarcais. Dando continuidade, vamos explorar a representação da protagonista transgressora na ficção de Helena Parente Cunha.

\section{O lugar da artista em Helena Parente Cunha}

Helena Parente Cunha apresenta uma ficção muito preocupada com a condição da mulher na sociedade brasileira. Seu romance, A mulher no espelho (1985), apresenta um jogo entre a tessitura da identidade da protagonista e o desnudamento das amarras patriarcais. Ao mesmo tempo em que a personagem vai se despindo dos valores tradicionais, a narrativa faz uma crítica do espaço da mulher. Esse romance se insere na tradição literária de questionamento da identidade de gênero, ao descrever uma protagonista submissa, que participa de um jogo com a mulher rebelde que a escreve. Tal duplicidade de "eu" aponta para os deslocamentos da identidade de gênero, descrita como não fixa, nem homogênea. Em As doze cores do vermelho (1988), Cunha brinca com o romance de formação feminino ao fazer uma paródia da construção da protagonista por meio de diferentes tensões no espaço da família patriarcal. Essa obra descreve a trajetória de uma pintora que faz reflexões acerca do seu pertencimento identitário desde menina, quando brincava com seus amigos. Com uma forma inovadora, narrada em três tempos concomitantes - passado, presente e futuro -, a autora explora diferentes deslocamentos femininos no plano estético e cultural. A mulher busca novos espaços para sua identidade artística fora do contexto da família, enquanto amplia seus conceitos de arte contemporânea.

Assim como Renata, essa protagonista torna-se um pesadelo para o marido e para as filhas ao valorizar sua carreira profissional. Entre as especificidades dessa identidade de gênero, sua tentativa de fugir das imposições patriarcais atravessa sua infância, juventude e fase adulta. Tal transitoriedade da identidade feminina faz parte do jogo metafórico da morte da mãe como crítica à opressão do patriarcado e contesta a identidade fixa e a família como sistema totalizante ou homogêneo.

Nesse caso, a preocupação feminista subverte as normas culturais que execravam mulheres que valorizassem sua carreira profissional, dando menos importância para o casamento. Com isso, a ficção de Helena Parente Cunha prega o abandono dos binarismos próprios do mundo patriarcal como saída para as homogêneas fórmulas familiares. Com tal foco, a obra brinca com 
a normatização dos papeis masculinos e femininos, pois "a identidade, como a de gênero, a sexual, ou qualquer outra, é produto tanto da cultura e do discurso, quanto da natureza que nos identifica na materialidade do corpo" (FUNK, 2011, p. 67).

Por ter a particularidade de ser desmontável, essa obra apresenta uma estrutura textual tripartida que proporciona diferentes leituras do trajeto da protagonista. Para cada módulo (capítulo), há três ângulos da história da protagonista: à esquerda, o passado vivido; ao centro, a vida presente; e à direita, seu futuro de liberdade. Nos três módulos, há um questionamento do fascismo das identidades fixas desde a infância: "Nós brincávamos de casinha comidinha de mãezinha das bonecas. Os meninos brincavam de soldado espingarda revólver de espoleta" (CUNHA, 1998, p. 14, Al)*1.

Por ser narrada por meio de uma linguagem artística extremamente fragmentada e poética, as ações da protagonista são reveladas sem uma sequência cronológica determinada. Em sua travessia pelos diferentes espaços sociais, ela apresenta uma postura crítica sobre o universo de normas e regras a serem enfrentadas. Contestadora, essa obra prioriza uma identidade feminina em movimento e questiona conceitos do humanismo liberal como totalização, verdade, identidade, certeza, centro, homogeneidade, dentre outros, num discurso pós-moderno que privilegia a diferença como um referencial de interpretação (HUTCHEON, 1991, p. 84).

$\mathrm{Na}$ busca de um espaço todo seu, a mulher prioriza explicitamente seu gosto por um terceiro espaço fora dos binarismos tradicionais: "Duas metades. Dois lados. Dois quartos. $\mathrm{O}$ apartamento de dois quartos" (CUNHA, 1998, p. 33, A3). Observa-se também que a opressão por uma escolha simplificada não faz parte do pertencimento da artista, que busca a liberdade só encontrada na arte. Essa forma de narrar o fascismo do mundo patriarcal pode ser vista como um questionamento da padronização dos papeis da mãe e da esposa.

Em sua trajetória, a protagonista se mostra completamente sufocada pelo casamento e passa a rever seus papeis sociais, por isso "ela lerá muitos medos e muitas coragens. O lado de lá e o lado de cá” (CUNHA, 1998, p. 21, A3). Assim, entre essas opções ela identifica um universo familiar opressor. Como na obra de Luft, esse romance opta por um deslocamento feminino metafórico e registra sua travessia pela morte. Após perceber que não consegue ajudar sua filha doente, ela opta por um deslocamento fatal e bate o carro. Como saída, ela só consegue enxergar a subjetividade de sua escolha "além dos dois lados o ápice estrelado da cordilheira" (CUNHA, 1998, p. 100, A2).

Fora da família, a protagonista completa um ciclo de identificação que só é possível porque sua identidade está sendo "construída multiplamente ao longo dos discursos, práticas e posições que podem se cruzar ou ser antagônicas" (HALL, 2000, p. 108). Por esse viés interpretativo, o processo de identificação dessa artista é fundamental para se identificar o projeto feminista que entrecruza o projeto artístico do romance. Ao optar por uma artista dinâmica e independente, mas em crise com sua vida familiar, esse romance descreve os impasses sofridos pelas mulheres que buscaram a liberdade econômica por meio da emancipação profissional.

Essa ideia de amplitude oferecida pelo texto é valiosa se vista como discurso crítico a tudo que é opressão à mulher. $\mathrm{O}$ fato de ela não mais ver a dicotomia que lhe oprime durante todo seu processo de crescimento mostra-se compensador, como se realmente ela estivesse para alcançar um novo estágio, sem extremos e que oferecesse mais opções para suas individualidades: "Você chega ao

*1 Como As doze cores do vermelho apresenta uma narrativa em três ângulos, usaremos, após o número de cada página, os seguintes códigos: Al, A2 e $A 3$, respectivamente, passado, presente e futuro. 
estacionamento. Sua mão trêmula pega as chaves do carro. Você liga o motor e passa a marcha e sai. E vai a toda velocidade. Para onde você vai?” (CUNHA, 1998, p. 105, A2). Ao mostrar uma protagonista que opta pelo abandono da família, a obra retoma o deslocamento feminino como saída da lógica social de gênero. Tal opção pode ser interpretada como uma falta de "âncora social" da mulher emancipada que busca um "nós" fora dos padrões familiares (BAUMAN, 2005, p. 33).

Nesse sentido, no plano artístico, As dozes cores do vermelho pode proporcionar um novo olhar para a identidade de gênero se visto como uma paródia do casamento tradicional. Assim, no plano ficcional, a mãe que abandona a família para experimentar uma liberdade pessoal projeta o caráter político dessa opção cultural, visto que identificamos uma personagem que foge de "esquemas predeterminados, coercitivos e repressores", para experimentar a independência própria de um corpo feminino liberado (XAVIER, 2007, p. 179).

Dessa forma, esse texto cumpre seu papel de denunciar e de propor a individualização da mulher como um outro lugar de gênero, visto que a travessia pela qual a protagonista se envereda representa a rejeição da norma. Com isso, há uma recusa da identidade de gênero tradicional. Tal construção é fruto de imposições culturais pois "a desigualdade de gênero e a opressão sexual não são fatos imutáveis da natureza, mas sim artefatos da história" (BUTLER, 2001, p. 144). Com essa protagonista, a autora opta por denunciar o sistema cultural que "naturaliza" o casamento e a maternidade como as únicas opções femininas.

Assim, por apresentar a trajetória de uma artista, as opções estéticas se confundem com as opções ideológicas, visto que a subversão e a ruptura das normas estão simbolicamente marcadas com as ações da protagonista. Isso significa que essa obra apresenta um "ziguezague" de eus que fissura a ortodoxia das representações sociais (RICHARD, 2002, p. 166). Assim, As doze cores do vermelho retoma a tradição do deslocamento feminino na ficção ao questionar a identidade fixa pela valorização da subjetividade da protagonista.

\section{Conside rações finais}

A partir do recorte desses dois romances e do conhecimento de outras produções de Luft, Cunha e das outras autoras citadas, podemos destacar que o deslocamento espacial da mulher é uma constante no romance contemporâneo e apresenta a particularidade de explorar a paródia como uma forma política de fazer literatura. Nos romances analisados, a mulher articula seu discurso fora do poder patriarcal ao repudiar a identidade de gênero fixa. Com esses movimentos, identificamos o repúdio à "dogmatização do feminino", sem deixar de lado "resíduos" e "rupturas" das diferentes identidades da mulher em jogo no processo cultural (RICHARD, 2002, p. 167).

Nesse sentido, Lya Luft e Helena Parente Cunha, por meio de suas obras literárias, intensificam a luta da mulher por espaços que se distanciam da opressão familiar. Portanto, com a morte das protagonistas, seja metafórica ou fisicamente, essas obras denunciam a opressão patriarcal por meio do efeito patético da morte. Assim, o texto literário assume uma condição pedagógica por destacar a opressão patriarcal como um dos motivos da morte, tornando visível e "risível" o processo de naturalização das regras de gênero que historicamente foram impostas. A morte como uma das direções seguidas durante o deslocamento da identidade de gênero das personagens confere ao signo "morte” um valor iniciático, uma vez que é a partir dela que a insurreição contra o modelo patricarcal se intensifica.

Como argumentado, o deslocamento da identidade de gênero pode ser lido como um lugar original de resistência feminista. Além disso, torna-se relevante a ideia de que uma identidade 
de gênero não está sujeita apenas à coerência interna de ser homem ou ser mulher, visto que a performance de gênero também pode ser uma ferramenta de contestação da lógica social. Daí ressaltarmos a pluralidade da representação de gênero como particularidade do romance contemporâneo, que desloca o fixo, visto que "o gênero não se constitui de maneira coerente ou consistente nos diferentes contextos históricos" (BUTLER, 2003, p. 20).

Assim, tanto em O quarto fechado como em As doze cores do vermelho, o olhar paródico pode ser lido pelo tom de zombaria com que se refere ao sistema patriarcal. Essas obras apresentam uma paródia do deslocamento da identidade de gênero como uma particularidade estética feminista. Nesse caso, a família patriarcal é o texto cultural que está sendo parodiado, pois as duas obras apresentam uma "forma intertextual que constitui, paradoxalmente, uma transgressão autorizada, pois sua irônica diferença se estabelece no próprio âmago da semelhança” (HUTCHEON, 1991, p. 95).

Esse deslocamento é retomado de diferentes formas como um lugar legítimo para a identidade da mulher. Com isso, em tais representações literárias, a proposta de mobilidade por trás da identidade de gênero ressalta uma estética própria do feminismo das diferenças, aquele que não está preocupado em construir uma oposição fixa, mas sim assinalar "registros heterogêneos, plurais e contraditórios, de identificação sexual, de representação social e significação cultural” (RICHARD, 2002, p. 155).

\section{REFERENCIAS BIBLIOGRÁFICAS:}

BAUMAN, Zygmunt. Identidade. Entrevista a Benedetto Vecchi. Tradução Carlos A. Medeiros. Rio de Janeiro: Jorge Zahar, 2005.

BUTLER, Judith. Problemas de gênero. Trad. de Renato Aguiar. Rio de Janeiro: Civilização brasileira, 2003. BUTLER, Judith. "Corpos que pesam: sobre os limites discursivos do sexo". In LOURO, Guacira Lopes. O corpo educado. Belo Horizonte: Autêntica, 2001.

CUNHA, Helena Parente. As doze cores do vermelho. Rio de Janeiro: Tempo Brasileiro: 1998.

DUARTE, Constância Lima. "Pequena história do feminismo no Brasil". In CARDOSO, Ana Leal; GOMES, Carlos Magno. Do imaginário às representações na literatura. São Cristóvão: Ed UFS, 2007. FUNCK, Susana. “O que é uma mulher?” In Cerrados. Brasília: Pós-graduação em Literatura, 2011, p. 65-74.

HALL, Stuart. A identidade cultural na pós-modernidade. Trad. de Tomaz Tadeu da Silva e Guacira Lopes Louro. 6” ed. Rio de Janeiro: DP\&A, 2006.

HALL, Stuart. “Quem precisa da identidade?” In: SILVA, Tomaz Tadeu da (org.). Identidade e diferença. Petrópolis: Vozes, 2000.

HUTCHEON, Linda. Poética do pós-modernismo. Trad. de Ricardo Cruz. Rio de Janeiro: Jorge Zahar, 1991. HUTCHEON, Linda. Uma teoria da paródia. Trad. de Teresa Louro Pérez. Lisboa: Edições 70, 1989. LUFT, Lya. O quarto fechado. 4a. Ed. São Paulo: Siciliano, 1991.

RICHARD, Nelly. Intervenções críticas. Tradução de Rômulo Monte Alto. Belo Horizonte: UFMG, 2002. XAVIER, Elódia. Que corpo é esse? O corpo no imaginário feminino. Florianópolis: Ed. Brasil, 2007.

ARTIGO RECEBIDO EM: 31 jan. 2012.

ARTIGO ACEITO EM: 19 mar. 2012.

REFER ÊN I A ELETRôn I CA: COMES, Carlos Magno. O Deslocamento Feminino no Romance Contemporâneo. Revista Criação \& Crítica, n. 8, p. 12-19, abr. 2012. Disponível em:<http://www.fflch.usp.br/dlm/criacaoecritica/ dmdocuments/CC_N08_CMGomes.pdf>. Acesso em dd mmm. aaaa. 